For chronic fissure in ano, surgical excision and suture has been practised with surprisingly good results. A stay suture is inserted at the proximal and distal extremities of the fissure which is made prominent by tension on each stay. The fissure is then easily excised with the subjacent portion of the subcutaneous external sphincter. Two or three figure-of-eight sutures of fine nylon are placed, one of which approximates the cut ends of the sphincter. A layer of gauze is wrapped round a small soft rubber tube and the sutures are tied lightly over it. The bowels are confined for six days and the dressing remains clean until the sixth day when the sutures are removed and an olive oil enema is given. The sutures are easily removed by cutting over the dressing. Liquid paraffin by mouth and local. Vaseline before defaecation are used for two subsequent weeks, and it is interesting to note that the writer has not seen fistula formation after this procedure. There is also an economy in hospital days as compared with wounds allowed to heal by second intention.

Time lost from work in the treatment of a minor disability, although of secondary significance to successful treatment, is nevertheless of major importance to the individual and to the community. The aim of the modifications in technique and management which have been described, has been to achieve cure or comfort in the shortest possible time. The guiding principle has been close attention to the smaller clinical and technical details.

\title{
TREATMENT OF ACUTE EMPYEMA THORACIS WITH INTRAMUSCULAR AND INTRAPLEURAL PENICILLIN
}

\author{
By W. A. Elliotr, M.D. (Camb.), M.R.C.P. \\ Trainee Specialist Physician \\ and \\ $\Varangle \quad$ B. A. Young, M.D.(Lond.), M.R.C.P. \\ Physician Superintendent, St Alfege's Hospital, Greenwich
}

This paper is based on a series of 22 cases of acute empyema admitted to this hospital between March, 1945, and Auguist, 1947. The underlying disease was lobar pneumonia in 18 cases, bronchopneumonia in one case, lung abscess in one case and neoplasm in two cases. The duration of symptoms before admission to hospital varied from three days to six weeks. (The onset of symptoms is reckoned from the first day on which the patient felt ill, as the date of onset of the empyema cannot be accurately determined.)

While acute toxaemic symptoms were present, the patients were given intramuscular penicillin in doses sufficient to maintain a continuous bacteriostatic concentration of the antibiotic in the blood-stream (usually 60,000 units four-hourly). In addition, the pleural cavity was aspirated as completely as possible through a wide bore needle on alternate days and intrapleural penicillin (usually 250,000 units) was injected. (Smaller doses were given in some of the earlier cases in the series.) The fluid withdrawn was cultured and the sensitivity to penicillin of the organisms grown, was estimated. Breathing exercises were started as early as possible in all cases.
This method of treatment gave good results in I 4 of the pneumonic cases and in the lung abscess case. Details are given in the table below. The average time spent in hospital in these cases was 52 days; the average time after this for the chest radiographs to become clear was five weeks. Good functional results were obtained in all 15 cases. In four other pneumonic cases, rib resection and drainage was carried out after a course of intramuscular and intrapleural penicillin. In one of these four cases, the culture of the pus from the pleural cavity grew bacterium coli which was resistant to penicillin. In another case, in which

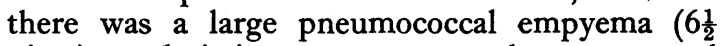
pints) on admission, a pyo-pneumothorax occurred during treatment. The remaining two cases which were treated surgically, were early in the series and received relatively small doses of penicillin ; one of them having no intramuscular penicillin. In the light of our later experience we consider that both these cases would probably have cleared up without operation had larger doses of penicillin been given. The remaining pneumonic case improved considerably with intramuscular and intrapleural penicillin and the patient was dis- 


\begin{tabular}{|c|c|c|c|c|c|c|c|c|c|}
\hline 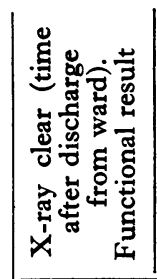 & 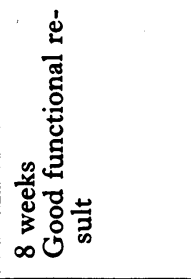 & 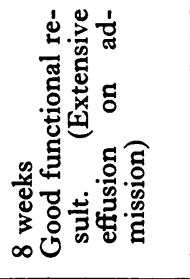 & 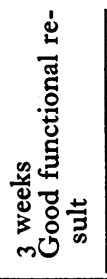 & 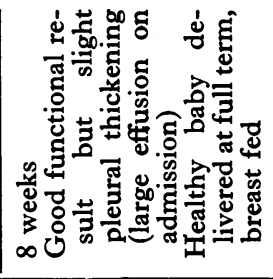 & 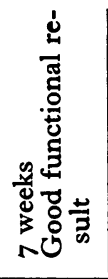 & 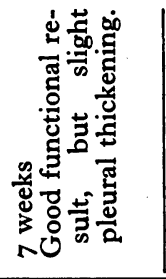 & | & 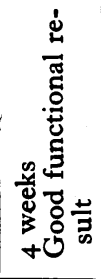 & \\
\hline 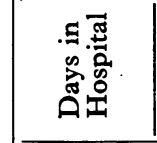 & $\hat{a}$ & ț & 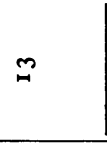 & $\infty$ & 足 & 2 & in & in & $\dot{s}$ \\
\hline 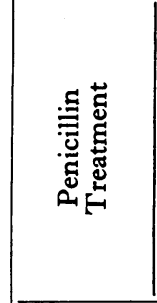 & 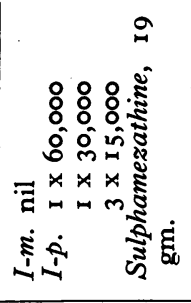 & 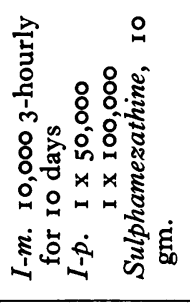 & 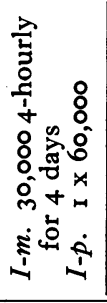 & 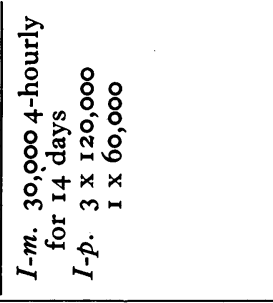 & 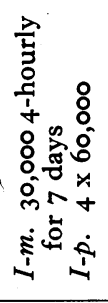 & 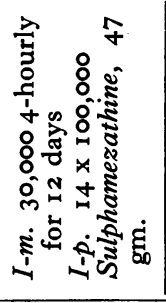 & 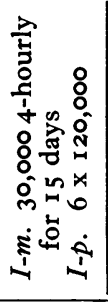 & 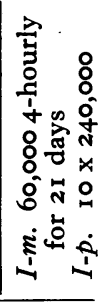 & 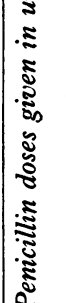 \\
\hline 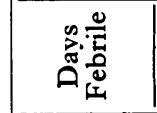 & + & $\Xi$ & $m$ & $m$ & \pm & in & $\hat{N}$ & $\Xi$ & . \\
\hline 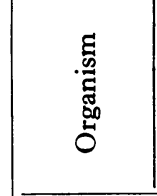 & 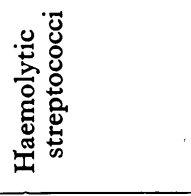 & 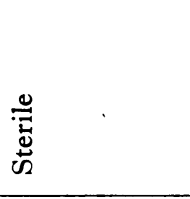 & 营 & 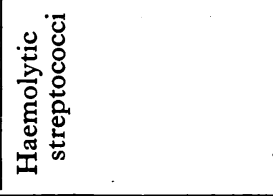 & 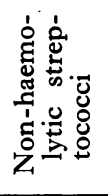 & 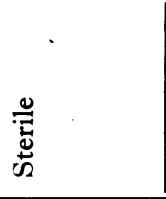 & 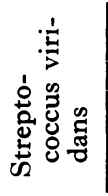 & 总 & 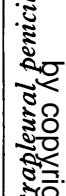 \\
\hline 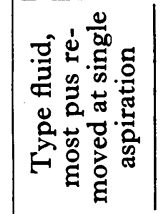 & 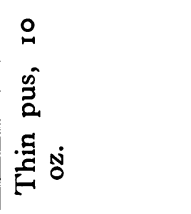 & 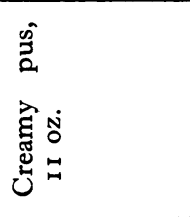 & 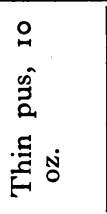 & 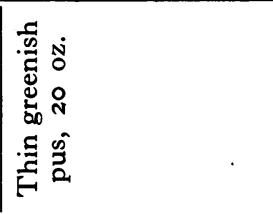 & 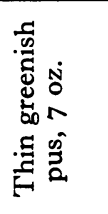 & 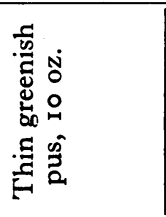 & 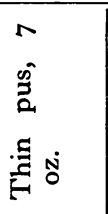 & 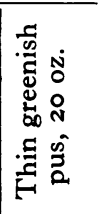 & $\begin{array}{l}11 \\
\dot{5} \\
\dot{3} \\
\dot{3}\end{array}$ \\
\hline 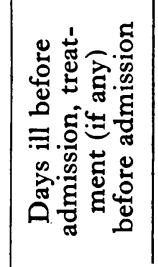 & + & 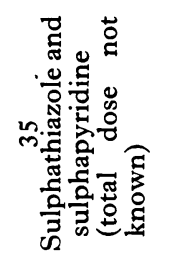 & 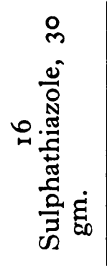 & $m$ & 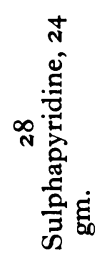 & m & 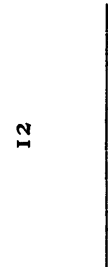 & $\infty$ & 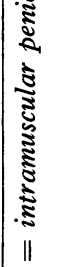 \\
\hline 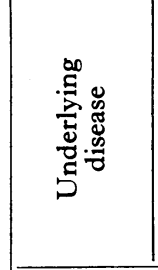 & 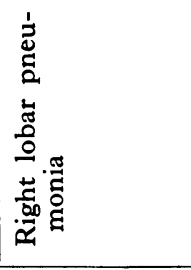 & 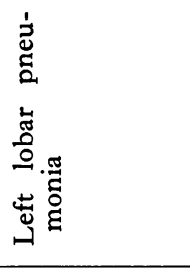 & 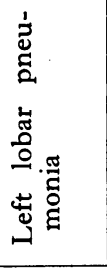 & 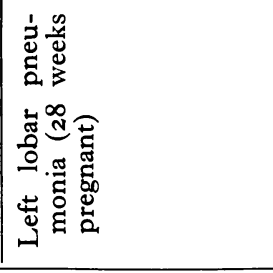 & 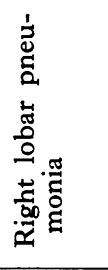 & 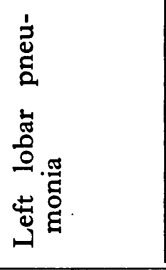 & 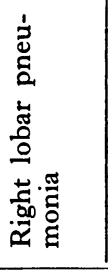 & 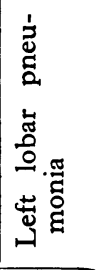 & $\underset{5}{i}$ \\
\hline 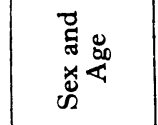 & II. & 珐宕密 & ¿ंt & 压 & $\sum$ i & $\dot{2} \&$ & $\Sigma i$ & $\sum \dot{\Sigma}$ & \\
\hline$\dot{\dot{z}}$ & i & $\dot{m}$ & $\dot{\sigma}$ & 0 & 1 & $\infty$ & $\dot{\circ}$ & $\dot{\Delta}$ & \\
\hline
\end{tabular}




\begin{tabular}{|c|c|c|c|c|c|c|c|}
\hline 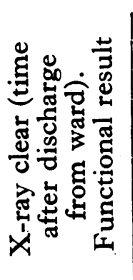 & 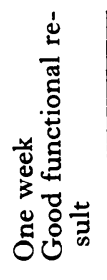 & 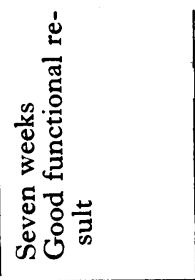 & 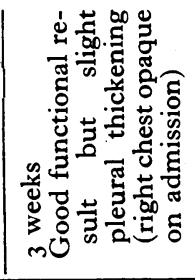 & 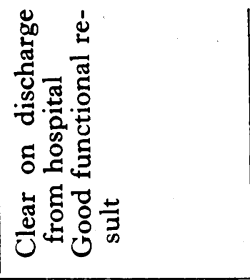 & 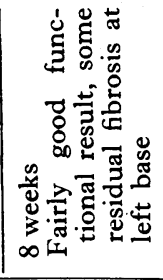 & 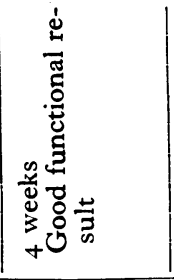 & 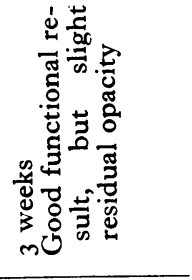 \\
\hline 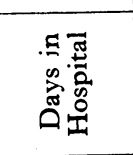 & \pm & 吕 & in & $\infty$ & iे & in & in \\
\hline 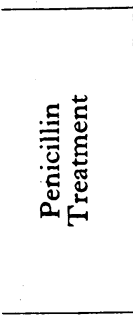 & 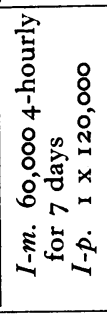 & 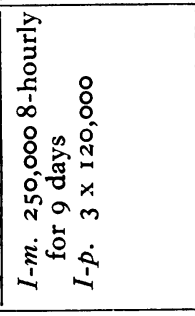 & 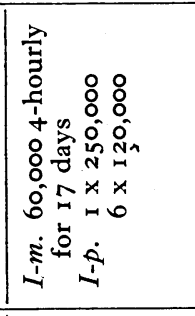 & 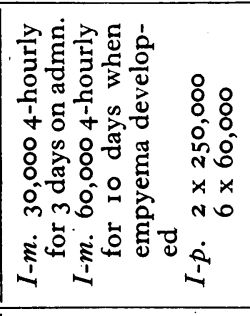 & 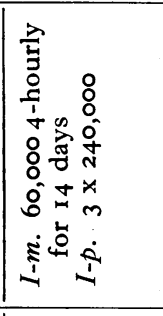 & 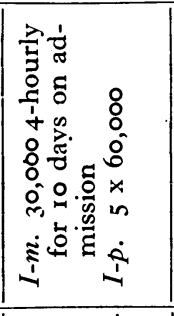 & 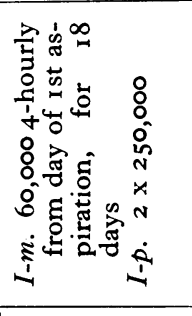 \\
\hline 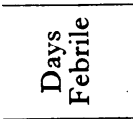 & $m$ & I & n & 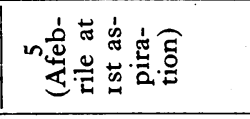 & $z$ & 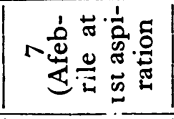 & 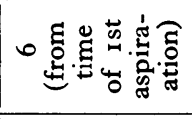 \\
\hline 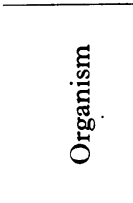 & 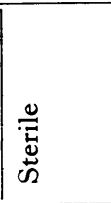 & 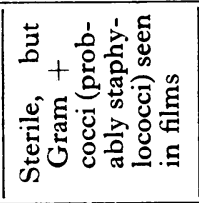 & 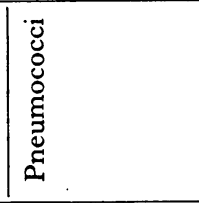 & 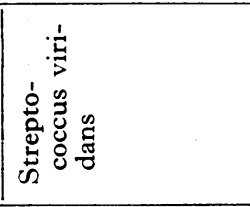 & 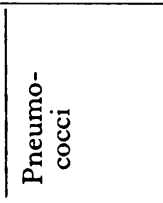 & 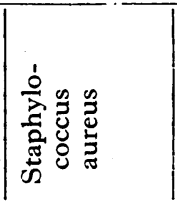 & 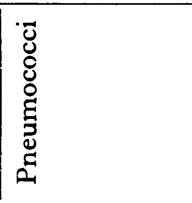 \\
\hline 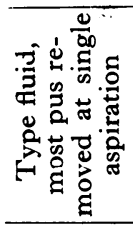 & 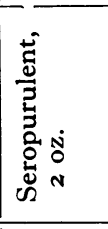 & 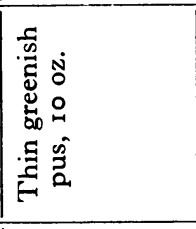 & 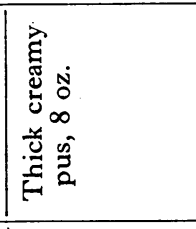 & 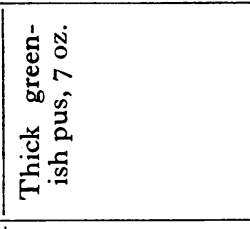 & 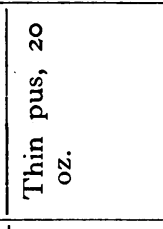 & 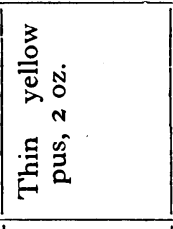 & 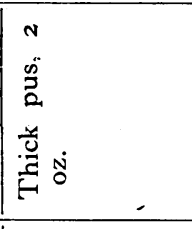 \\
\hline 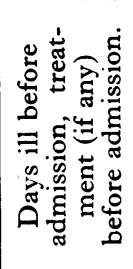 & $a$ & 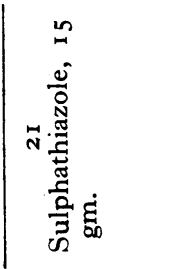 & 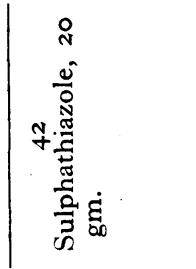 & \pm & 웅 & in & 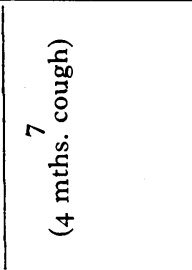 \\
\hline 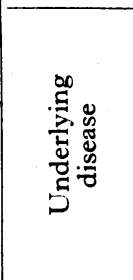 & 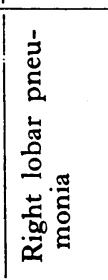 & 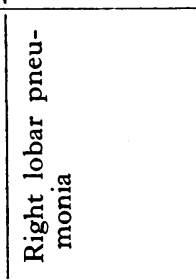 & 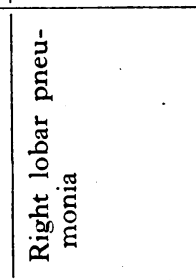 & 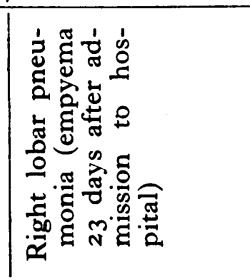 & 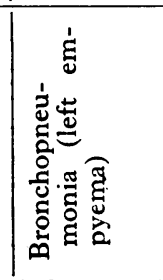 & 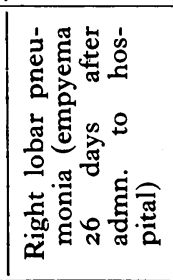 & 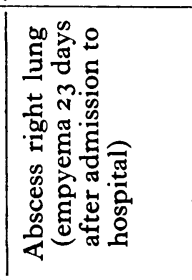 \\
\hline 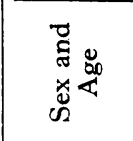 & $\dot{x}^{\prime} n$ & $\not x^{\infty}+$ & si in & ¿ं8 & $\Sigma^{\dot{2} \infty}$ & $\sum \underset{\text { in }}{\dot{m}}$ & ¿் \\
\hline$\dot{\mathrm{g}}$ & ¿ & $\dot{m}$ & $\dot{\phi}$ & $\infty$ & $\dot{\sigma}$ & $1 \stackrel{8}{1}$ & | ส่ \\
\hline
\end{tabular}

뭉

음

융

흐

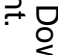

立

$\frac{0}{8}$

ò

릉

혹

욱

ริ

욱

을

N

N

श्

@

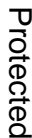


charged from hospital after 29 days, but she was re-admitted with acute purulent bronchitis 23 days later and died the same day. The post-mortem examination showed that the empyema had completely resolved. In the two cases in which neoplasm was the underlying disease (one secondary sarcoma of lung and the other bronchial carcinoma), the symptoms and signs caused by the empyema disappeared with treatment and there was a considerable temporary improvement in the general condition of the patients. One of them later died from bronchial carcinoma and the post-mortem examination showed that the empyema had almost entirely resolved, leaving only a few adhesions in the pleural space.

\section{Case Records}

For cases successfully treated with intramuscular and intrapleural penicillin see pages 476 and 477 .

Cases treated with rib resection and drainage after a course of intramuscular and intrapleural penicillin.

Case I. Male, aged 70. Admitted to hospital with left lobar penumonia ; four days ill before admission. Given 48 grammes sulphamezathine with considerable improvement, but developed pneumococcal empyema eight days after admission. Thin pus, which rapidly thickened. Most pus removed at single aspiration was I $_{5} \mathbf{~ o z}$. $\mathrm{Had}$ one injection of 60,000 units intrapleural penicillin followed by eight injections of 20,000 units intrapleural penicillin on alternate days. No intramuscular penicillin. The pus rapidly became sterile and thickened. Rib resection was done after the course of intrapleural penicillin. A good functional result was obtained, but the radiograph taken four weeks after operation showed some pleural thickening and slight fibrosis of lung.

Case 5. Male, aged 52. Admitted to hospital with right lobar pneumonia and empyema ; four days ill before admission. Pus from pleural cavity grew staphylococcus aureus. Most pus removed at single aspiration was 10 oz. Thin pus on admission. Treated with 24 grammes sulphathiazole followed by intramuscular penicillin, 30,000 units four-hourly for eight days. One injection of 150,000 units intrapleural penicillin and one of 60,000 units intrapleural penicillin. The pus rapidly thickened and became sterile. Rib resection was then done; the patient was afebrile three weeks after operation. Four weeks after operation the chest $\mathrm{X}$-ray was practically clear.

We consider that both these cases would probably have cleared up without operation had larger doses of penicillin been given.

Case 14. Female, aged 33. Admitted to hospital with left empyema, the pus from which grew . B. Coli, which was resistant to penicillin. The patient was therefore treated by rib resection and drainage when the pus had thickened. Six weeks after operation the chest $\mathrm{x}$-ray was practically clear and there was a good functional result.

Case 15. Female, aged 35. Admitted to hospital with left lobar pneumonia and pneumococcal empyema ; I4 days ill before admission. Treatment was started with intramuscular penicillin 60,000 units four-hourly and intrapleural penicillin, 250,000 units on alternate days, but the

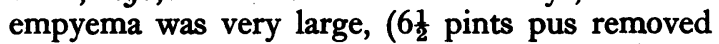
at one aspiration) and a pyo-pneumothorax occurred during treatment. Rib resection and drainage was therefore done, when the pus had

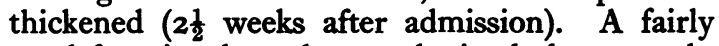
good functional result was obtained eleven weeks after operation, but there was some residual pleural thickening.

Pneumonic case in which Empyema resolved, but which death occurred later from Acute Purulenf Bronchitis.

Case 9. Female, aged 65. Right lobar pnetse monia with empyema, 28 days ill before admission to hospital. Seropurulent pleural fluid which was sterile. Most pus removed at single aspiration was $20 \mathrm{oz}$. Intramuscular penicillin, 60,000 units four-hourly for 14 days. Four injections of 120,000 units intrapleural penicillin. Was discharged convalescent after 29 days, but was readmitted to hospital 23 days later and died the same day from acute purulent bronchitis. The post-mortem examination showed that the empyema had completely resolved.

\section{Cases of Empyema complicating Neoplasm}

Case 17. Male, aged $5 \mathrm{I}$. Neoplasm of left bronchus complicated by pneumococcal empyema. Three ounces pus removed at single aspiration. Intramuscular penicillin, 60,000 units fourhourly for 28 days. Five injections of 240,000 units intrapleural penicillin on alternate days. Considerable temporary improvement, but died 53 days after admission from extensive carcinoma, originating in left bronchus. The post-mortem examination showed that the empyema had almost entirely resolved, leaving only a few adhesions in the pleural space.

Case 21. Male, aged 49. Right leg amputated for sarcoma, two years before present illness. Admitted to hospital with secondary sarcoma of 


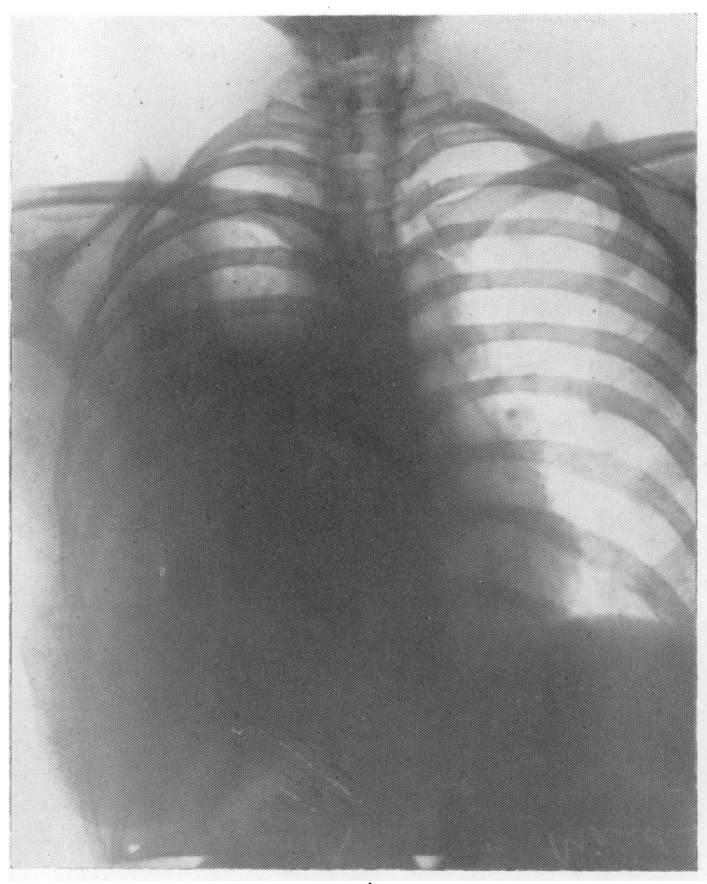

Case 6.-On admission.

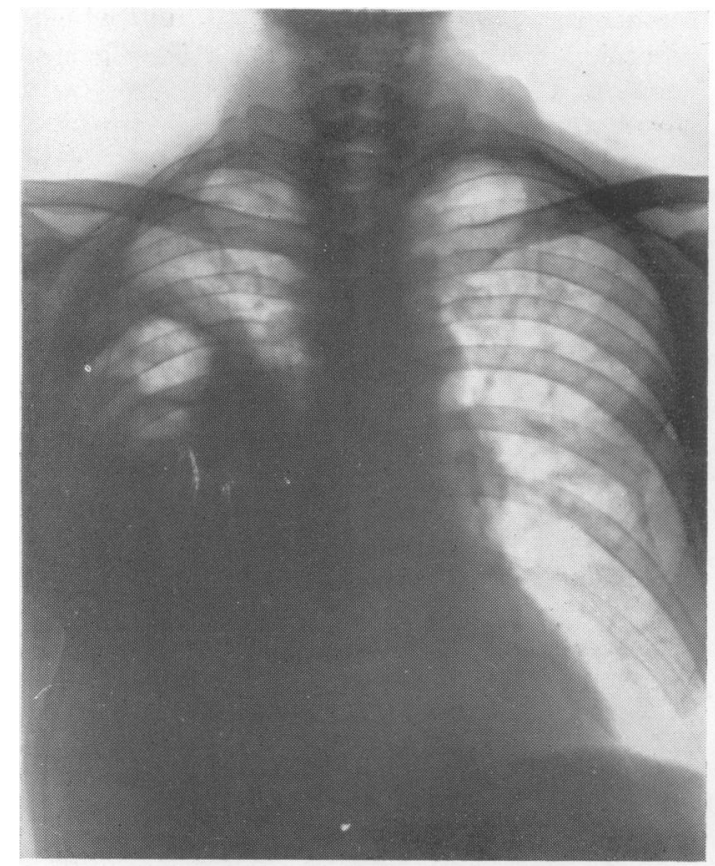

Case 7.-On admission.

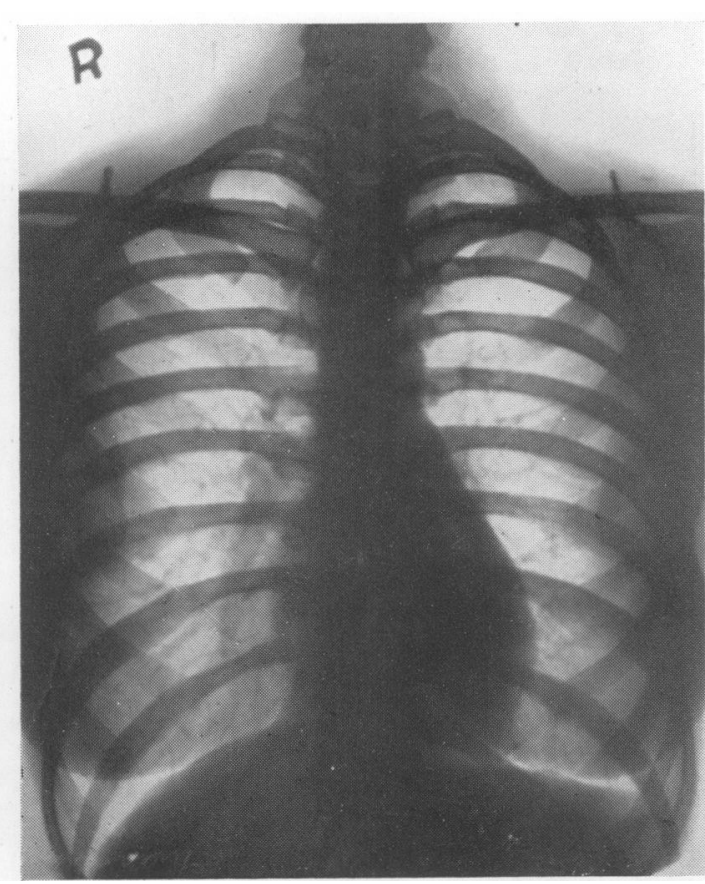

Case 6.-I I months later.

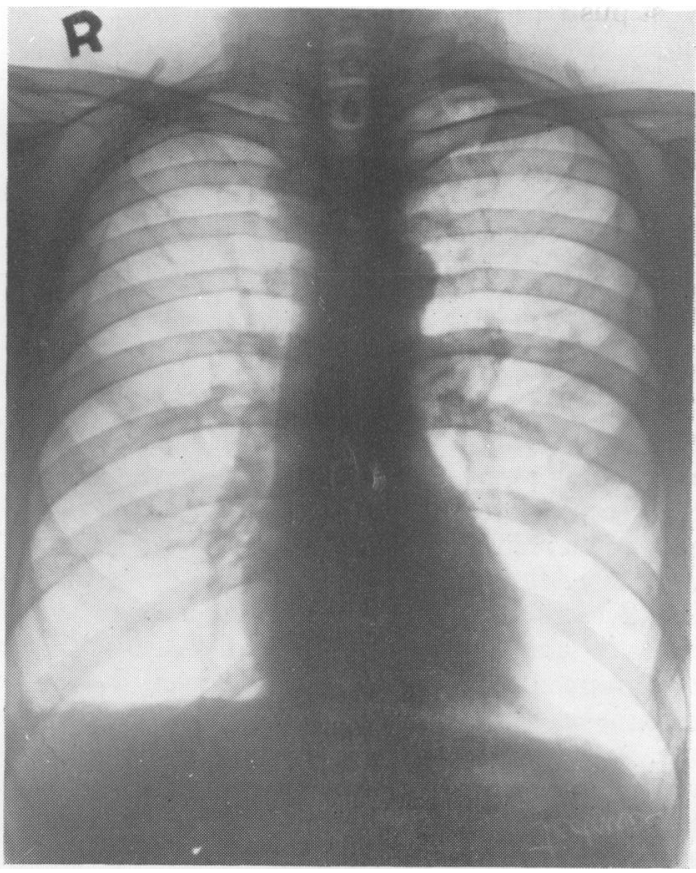

Case 7.-1 5 months later. 


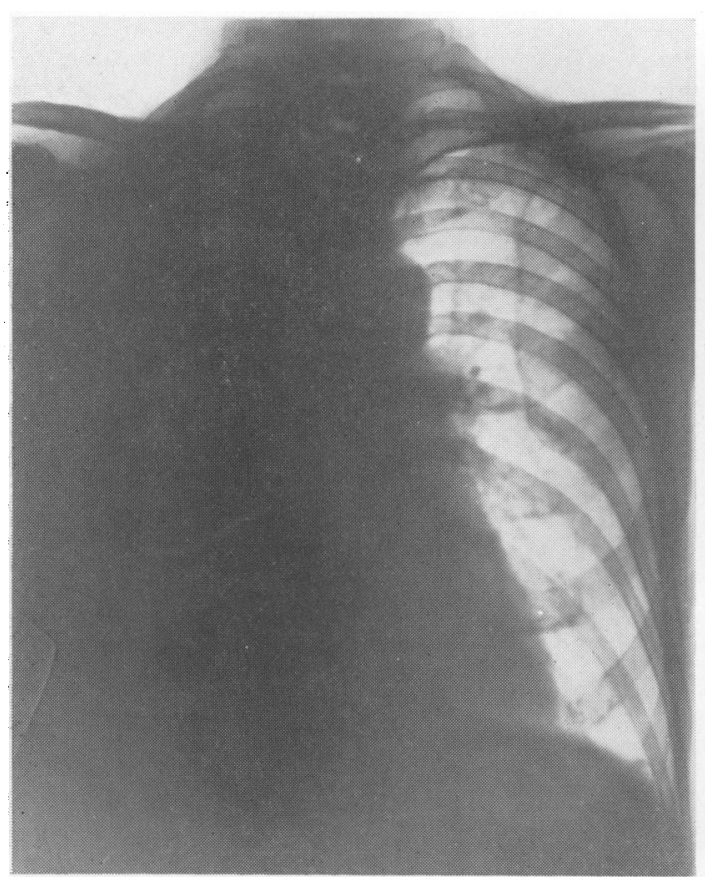

Case 16.-On admission.

both lungs, with right-sided empyema, the pus from which grew B. Pfeiffer which was penicillin sensitive. Thick pus; two ounces removed at single aspiration. Intramuscular penicillin 60,000 units four-hourly for eight days. Six injections of 250,000 units intrapleural penicillin on alternate days. Considerable improvement in general condition; symptoms and signs caused by empyema disappeared. Patient returned home after 47 days in hospital.

\section{Discussion}

Butler and others (1944) treated 18 cases of acute empyema by aspiration and the injection of intrapleural penicillin on alternate days. Penicillin sensitive organisms were grown in 17 of these cases ; in the remaining case the culture of the pleural fluid was sterile. The dose of intrapleural penicillin used by these authors was relatively small (usually 20,000 units or less) and no intramuscular penicillin was given, because the supply of the antibiotic was limited at that time. The results in this series of cases were only moderately satisfactory and pleural thickening occurred in several of them. Although the small doses of intrapleural penicillin used were sufficient to sterilize the pus, recurrence of infection occurred in four cases and in other cases minute

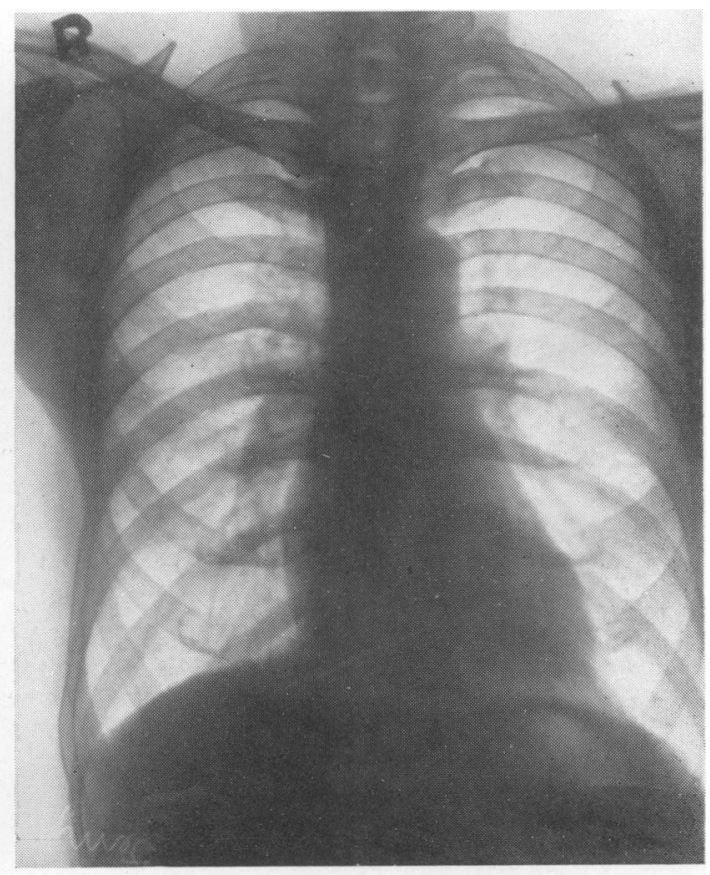

Case $16 .-8$ months later.

gram-positive cocci were repeatedly found in films after sterilization. The amount of intrapleural penicillin given would be insufficient to produce a continuous bacteriostatic level in the blood-stream; hence the antibiotic would not reach the underlying disease.

Florey and Heatley (1945) found that injection of 240,000 units of penicillin into a pleural cavity after aspiration of an effusion gave a bacteriostatic concentration of the drug in the bloodstream for about 48 hours. Roberts and others (I945) pointed out that absorption through the walls of an established empyema cavity might be slower than through the healthy pleura. These writers treated 12 cases of acute empyema with aspiration and intrapleural penicillin as a preliminary to rib-resection and drainage. In only one of these twelve cases was the empyema in the early invasive stage when treatment was started. The doses of intrapleural penicillin used were small, the average being 30,000 units initially and then 20,000 units at $48-72$ hours intervals. No intramuscular penicillin was given. These authors found that poorly staining bacteria might be seen in a gram film after the pus had become sterile. In two such cases, recrudescence of the infection occurred and the writers therefore recommended that at least three and preferably 
more injections should be given subsequent to sterilization.

Fatti, Florey and others (1945) treated 24 cases of acute empyema with penicillin, using various techniques. The technique which they found most successful was repeated aspiration and the injection of intrapleural penicillin, followed by intercostal drainage and the instillation of further doses of penicillin. Intercostal drainage was done as soon as the effusion became frankly purulent. These authors did not give intramuscular penicillin, but relied on using relatively large doses of intrapleural penicillin, $(240,000$ units every second day before intercostal drainage and 60,000 units twice daily in the toxaemic phase after intercostal drainage) to maintain a continuous bacteriostatic concentration of the drug in the bloodstream. Although these writers considered that early intercostal drainage was the method of choice in the treatment of acute empyema, they pointed out that it had two diasdvantages :(i) it was more difficult to ensure continuous retention of penicillin with this method than when aspirations on alternate days were being done and (ii) the frequent interference for instillation of penicillin favoured the introduction of air and collapse of the lung and prevented the fluid instilled from coming in contact with the whole of the affected pleural surfaces.

Brock and Holmes Sellors (1947) stated that in the early formative stages of pleural suppuration drainage was both unnecessary and dangerous and that penicillin therapy was most likely to be successful in early cases. For mature empyema they recommended rib-resection and drainage. They emphasized the importance of breathing exercises based on active, powerful and concentrated inspiratory efforts. These exercises could be started from the onset of the condition.

Our series of cases shows that good results can be obtained by a combination of intramuscular penicillin with repeated aspiration and injection of intrapleural penicillin in acute empyema due to sensitive organisms, provided that treatment is begun early in the disease and that the size of the effusion is not unduly large. Unless the possibility of empyema is continually borne in mind when pneumonia is being treated with penicillin, it may be overlooked in its early stages. In two cases in our series, the empyema appeared while the patient was afebrile. In one of these, the pleural fluid was seropurulent and grew Staphylococcus Aureus on culture; in the other the fluid was thick, greenish pus and grew Streptococcus Viridans.

We consider that while acute toxaemic symptoms are present, intramuscular penicillin should be given in addition to intrapleural penicillin, as this method ensures that the underlying disease causing the empyema is adequately treated. Our patients received intramuscular penicillin for from 7-21 days according to the duration of the acute toxaemic phase. The dose given in most cases was 60,000 units four-hourly, which we have found to maintain a continuous bacteriostatic concentration in the blood-stream even in cases where no intrapleural penicillin is being administered.

The pleural cavity must be aspirated as completely as possible through a wide-bore needle. Penicillin does not mix readily with purulent fluids and it should therefore be given intrapleurally in $20 \mathrm{ml}$. of normal saline. In order to ensure the maximum local affect and to prevent a recurrence of infection, we consider that large doses of intrapleural penicillin should be given. In most of our cases doses of 250,000 units were given on alternate days until no fluid was obtained on aspiration. The maximum number of aspirations necessary in any one case was 14 .

Breathing exercises of the type recommended by Brook and Holmes Sellors (1947) should be started as soon as the patient is able to do them.

\section{Summary}

Twenty-two cases of acute empyema thoracis were treated with intramuscular penicillin combined with repeated aspirations and the injection of intrapleural penicillin. This series of cases shows that good results can be obtained by this method in acute empyema due to penicillin sensitive organisms, provided that treatment is begun early in the disease and that the size of the effusion is not unduly large.

The importance of early diagnosis has been emphasized ; also the necessity for giving adequate doses of penicillin both by the intramuscular and the intrapleural route. Breathing exercises must be started early to obtain good functional results.

\section{BIBLIOGRAPHY}

BROCK, R. C., HOLMES SELLORS, T. (1947), Proc. roy. Soc. Med. 40, 645 .

BUTLER, E. C. B., PERRY, K. M. A., VALENTINE, F. C. O. (1944), Brit. Med. F. ii, 171 .

FATTI, L., FLOREY, M. E., JOULES, H., HUMPHREY, J. H., SAKULA, J. (1946), Lancet $i, 257$ and 295. FLOREY, M. E., HEATLEY, N. G. (1945), Lancet i, 748. ROBERTS, J. E. H., TUBBS, O. S., BATES, M. (1 945) Lancet i, 39. 